\title{
EFFECT OF LARGE PLASTIC STRAINS AND STRAIN GRADIENTS ON RESIDUAL STRESS RELAXATION IN SHOT PEENED IN100
}

\author{
Dennis J. Buchanan ${ }^{2}$ and Reji John ${ }^{1}$ \\ ${ }^{1}$ Materials and Manufacturing Directorate \\ Air Force Research Laboratory (AFRL/RXCM) \\ Wright-Patterson AFB, OH 45433-7817 \\ ${ }^{2}$ University of Dayton Research Institute \\ Dayton, OH 45469-0020
}

Keywords: shot peening, residual stress, modeling, Ni base superalloy, IN100

\begin{abstract}
Surface treatment processes, such as shot peening, are routinely used by several manufacturing industries (automotive, aerospace, medical, etc.) to impart compressive residual stresses onto the surface of metal components to increase damage tolerance and fatigue life. These compressive stresses are engineered into components to delay initiation of surface cracks and retard crack growth rate thereby improving fatigue life. In addition, the plastic deformation resulting from the shot peening process hardens the material increasing the yield strength and elastic stress range. For elastic material response, accurate fatigue life estimates that include credit for residual stresses are possible for complex geometries with complicated load histories. However, when a shot peened component is subjected to elevated temperatures or cyclic loading, thermal relaxation and cyclic plasticity, respectively, produce inelastic material response from which residual stresses may change continuously. When the material response is inelastic, taking full credit for compressive residual stresses in fatigue models would result in a nonconservative prediction. As a result, designers are reluctant to incorporate any compressive residual stresses into fatigue life predictions of turbine engine components, subject to elevated temperatures and inelastic loading conditions. This paper investigates relaxation of shot peened residual stresses in IN100 when subjected to applied stress profiles that produce large plastic strains and strain gradients in laboratory test samples. Model predictions supported by experiments results are presented to explain that redistribution of residual stress depth profiles are a function of geometry and applied stress/strain profile.
\end{abstract}

\section{Introduction}

In comparing and contrasting the capability of high temperature structural materials, particularly nickel-base superalloys, we often reference their mechanical behavior performance when subject to tensile, fatigue, or creep loading. However, modern components and structures often experience complex thermal and mechanical loading histories with sometimes larger than expected magnitudes that may not have been intended in the original design. Surface treatment processes such as shot peening (SP), low plasticity burnishing (LPB), and laser shock peening (LSP) provide some measure of protection against early crack initiation and retardation of crack growth by imparting compressive residual stresses onto the surface of components. Unfortunately, these beneficial compressive surface residual stresses are not static. Numerous research studies [1-11] have shown that residual stresses generated via surface treatment processes relax when subjected to elevated temperature exposure or mechanical loading. Therefore, the challenge to design damage tolerant components requires designers to incorporate residual stress relaxation models into their existing approach to life prediction of components subject to complicated thermomechanical loading histories.

\section{Background on Residual Stress Relaxation}

McClung[12] provides a thorough survey of residual stress literature and highlights many important issues related to relaxation related to fatigue response. For component applications subject to moderate temperatures and elastic stresses, residual stresses are static or change predictably with applied loading [4-5, 9-10]. However, nickel-base superalloys used in gas turbine engine applications typically experience temperatures approaching 50-60 percent of their melting temperature, and applied stresses approach or exceed the yield strength. Under elevated temperatures and high stress loading conditions, plastic deformation may significantly alter the as-peened residual stress depth profile.

Cao et al. [4] describes thermomechanical relaxation as a twostage process, in which the first stage is a shakedown of initial residual stresses described by a monotonic stress-strain law, and a second stage that is slower and is described by a cyclic softening related to the logarithm of applied cycles. Another multistage approach by Holzapfel et al. [5] describes residual stress relaxation as three different stages; (1) relaxation due to specimen heating, (2) relaxation during the first cycle, and (3) relaxation with the logarithm of applied cycles. Another method by Lu et al. [8] performs shakedown analysis using finite elements with a cyclic plasticity model that incorporates kinematic hardening, followed by a scheme to advance the state variables under constant amplitude loading. Prevéy $[1,6]$ reasons that the rate of residual stress relaxation and the amount of relaxation is directly correlated to the level of cold work in surface-treated Ti-6Al-4V and IN718. Furthermore, Buchanan et al. [13] reported that LSP surface treatment retains a higher percentage of the initial residual stress profile over that of SP when subject to thermal exposure. The higher retention of residual stress in LSP samples was attributed to a lower level of cold work.

As designers push the limit for operation of components at higher temperatures and stresses, additional issues arise with respect to retention of beneficial compressive surface residual stresses. The first issue is relaxation associated with large plastic strains. Only a limited number of studies have investigated residual stress relaxation under large magnitude stresses and strains. Vöhringer [14] in steel, Kirk [15] in copper and nickel, Prevéy et al. [16] in IN718, and Buchanan and John [17] in IN100 investigated 
residual relaxation and stress reversal subject to large plastic strains. Under large plastic strain, these studies have shown that the residual stress profile in these simple laboratory samples can be reversed resulting in tensile residual stresses on the surface.

The second issue, which is more relevant to actual components and structures, is the applied stress-strain gradient profile that is typically present in notches or under combined loading. Figure 1 is a schematic showing three standard laboratory test samples under simple uniaxial or bending applied loading conditions and the resulting stress profiles inside the body. In short, the uniform loading has a constant profile that is distributed throughout the entire cross-section. However, the notch sample has peak values at the root of the notches and a lower than nominal value at the center. In contrast, the bending sample has peak values of opposite sign on the outside surfaces and zero at the center of the sample. How these applied stress profiles combine with the internal residual stress profile and affect relaxation of residual stresses in these geometries are addressed in this paper.

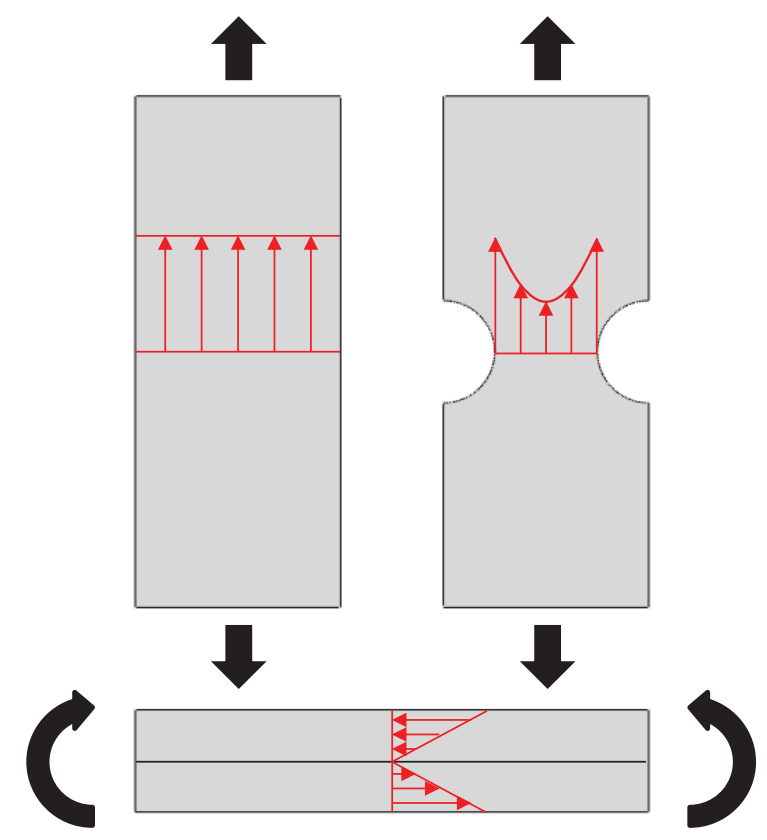

Figure 1. Schematic representation of applied stress states in simple geometries: (a) uniform, (b) stress gradient at notch, and (c) stress gradient under bending.

\section{Material Description of IN100}

IN100 is a powder metal (PM) nickel-base superalloy. The nominal chemical composition of IN100 is $12.4 \mathrm{Cr}, 18.5 \mathrm{Co}, 4.7 \mathrm{Ti}$, 5.5Al, 3.2Mo, $0.8 \mathrm{~V}, 0.07 \mathrm{Zr}, 0.07 \mathrm{C}$, and $0.02 \mathrm{~B}$ (wt \%). IN100 has a face-centered cubic (FCC) structure with an average grain size of approximately $15 \mu \mathrm{m}$. In FCC structures such as this IN100 alloy there are aluminum $(\mathrm{Al})$ atoms at the crystal corners and nickel $(\mathrm{Ni})$ in the center of each face of the crystal which make up the $\mathrm{Ni}_{3} \mathrm{Al}$ structure. The microstructure is composed of a continuous gamma $(\gamma)$ matrix, and a cubic gamma prime $\left(\gamma^{\prime}\right)$ morphology. The cubic gamma prime is responsible for the excellent creep resistance of this alloy. The gamma prime is strong and ductile which limits dislocation interaction and movement through the microstructure. Additional details about the baseline microstructure are described in the literature [18]. The monotonic true stress - true stain response for IN100 at two temperatures, $23{ }^{\circ} \mathrm{C}$ and $650{ }^{\circ} \mathrm{C}$, is shown in Figure 2 . The tensile tests were performed in stroke control at a rate of $0.045 \mathrm{~mm} / \mathrm{s}$ with an extensometer to capture strain measurements. Although the elastic modulus and ultimate tensile strength are dependent on temperature, the $0.2 \%$ offset yield strength and strain to failure are similar at $23{ }^{\circ} \mathrm{C}$ and $650{ }^{\circ} \mathrm{C}$.

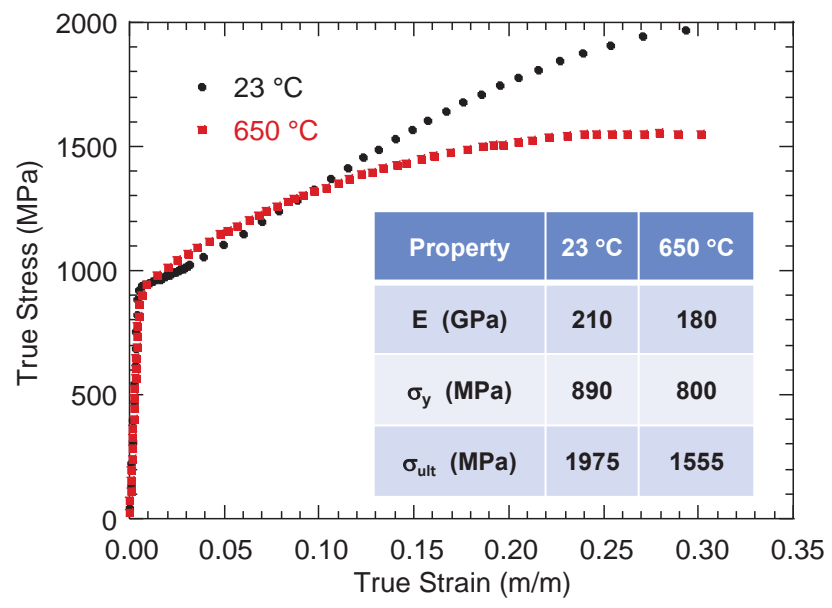

Figure 2. Monotonic true stress-strain for IN100 at $23{ }^{\circ} \mathrm{C}$ and $650{ }^{\circ} \mathrm{C}$.

\section{Residual Stress Relaxation in IN100}

A major issue is the hazard of extrapolating residual stress relaxation behavior on small-scale surface treated laboratory specimens to the behavior of large-scale engineering components. In both the laboratory specimens and engineering components, residual stress profiles have to satisfy load equilibrium. Therefore, the volume of material or size of the component subjected to surface treatment has an impact on the shape of the residual stress depth profile. Figure 3 demonstrates how residual stress depth profiles must satisfy load equilibrium for different thicknesses, or volumes.

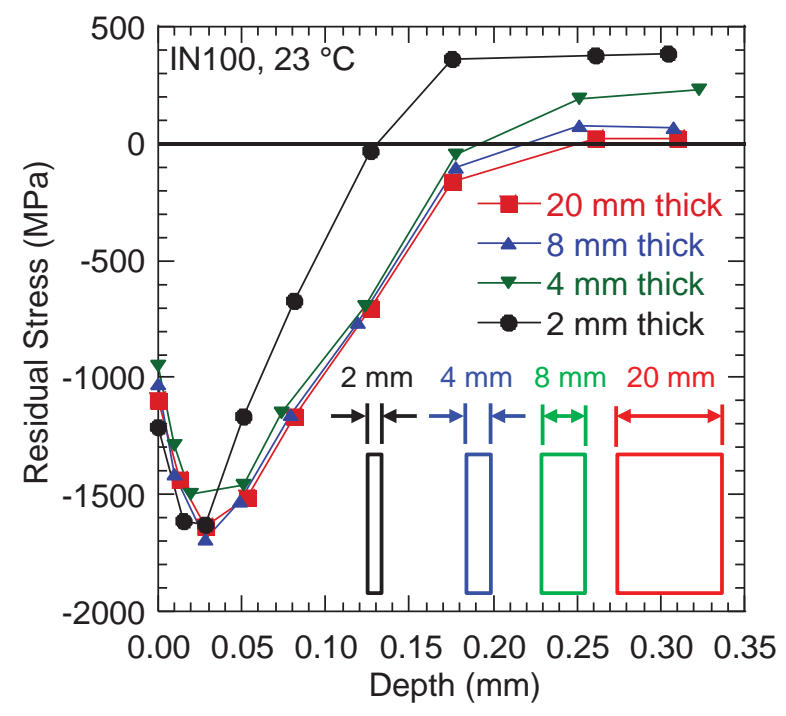

Figure 3. Measured residual stress depth profiles for different plate thicknesses in shot peened IN100. 
The inset image shows four different IN100 plates with thicknesses ranging from $2-20 \mathrm{~mm}$. Each plate was shot peened on both sides using identical peening parameters. All IN100 specimens were shot peened to an Almen intensity of $6 \mathrm{~A}-0+2$ using a MI-170-R (SAE 170 max. cast steel shot, regular) shot with $125 \%$ coverage.

The plot shows the residual stress depth profiles for the different thickness plates measured using x-ray diffraction and electropolishing for material removal. X-ray diffraction measurements were performed in accordance with SAE HS-784 employing the diffraction of manganese K-alpha radiation from the (311) planes of the IN100 FCC structure. The residual stress measurements were made at the surface and at nominal depths of $0.012,0.025,0.050,0.075,0.125,0.175,0.250$, and $0.350 \mathrm{~mm}$. All four plates have similar near surface $(0-0.03 \mathrm{~mm})$ depth profiles where shot peening impacts significant cold work and produces highly compressive residual stresses. Beyond this depth, the magnitude of compressive residual stress decreases for all curves with the $2 \mathrm{~mm}$ thick plate profile deviating from the other depth profiles. The transition from compressive to tensile residual stress exhibits a trend with plate thickness with the $2 \mathrm{~mm}$ thick plate transitioning at a much shallower depth. As a result, growth of small cracks in shot peened laboratory specimens could be faster than shot peened components with a greater thickness because of the difference in their sub-surface residual stress profiles. The final observation is the difference in the compensatory tensile residual stress in the interior of the plates. As the plate thickness decreases, the interior tensile residual stress has to increase to satisfy load equilibrium. In particular, the $20 \mathrm{~mm}$ thick plate has approximately $20 \mathrm{MPa}$ tension in the interior, while the $2 \mathrm{~mm}$ thick plate is close to $380 \mathrm{MPa}$ of tension in the interior. This large tensile residual stress can produce confounding fatigue behavior in laboratory specimens. The superposition of applied tensile stresses with residual stresses can produce tensile yielding in the interior while compressive stresses remain on the specimen surface.

\section{$\underline{\text { Relaxation under Uniform Stress Profile }}$}

The complete load-unload true stress versus true strain deformation response of cylindrical uniform gage section samples for three maximum applied stresses of interest in IN100 at $650^{\circ} \mathrm{C}$ are shown in Figure 4.

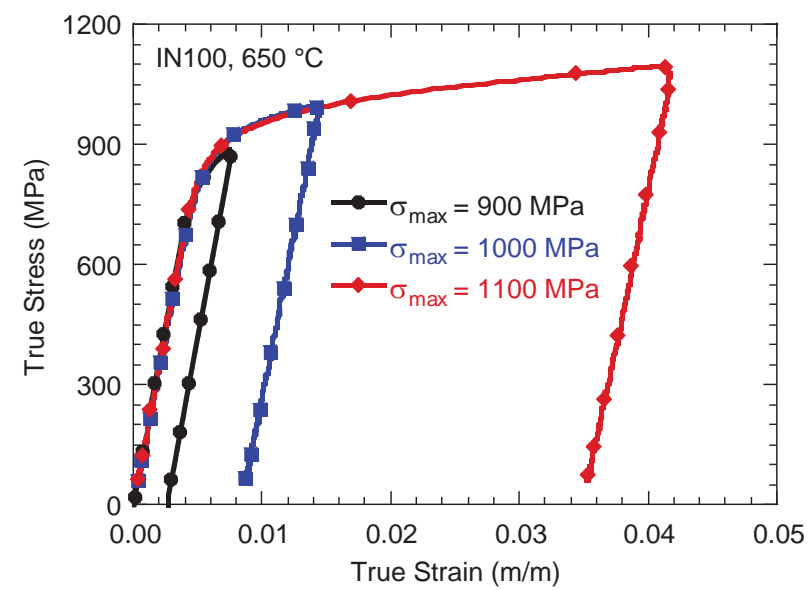

Figure 4. True stress-strain response and resulting plastic deformation for shot peened IN100 at $650{ }^{\circ} \mathrm{C}$ for different levels of maximum applied stress.
The tests were performed in a split-tube furnace under load control at a frequency of $0.33 \mathrm{~Hz}$ to match accompanying fatigue tests. Measured strain values were recorded using a hightemperature extensometer. All three specimens were tested in the shot peened condition and upon unloading resulted in gross plastic strain levels of approximately $0.002,0.008$, and 0.035 for the 900 , 1000 , and $1100 \mathrm{MPa}$ stress levels, respectively. The load-unload stress histories show the extent of plastic deformation across the entire uniform gage section of the specimen.

Measurements and predictions for retained residual stresses in IN100 shot peened cylindrical dogbone samples after fatigue testing at $650{ }^{\circ} \mathrm{C}$ are shown in Figure 5. The baseline profile is the as-peened residual stress profile averaged from multiple samples and the solid line is the profile input into the finite element model.

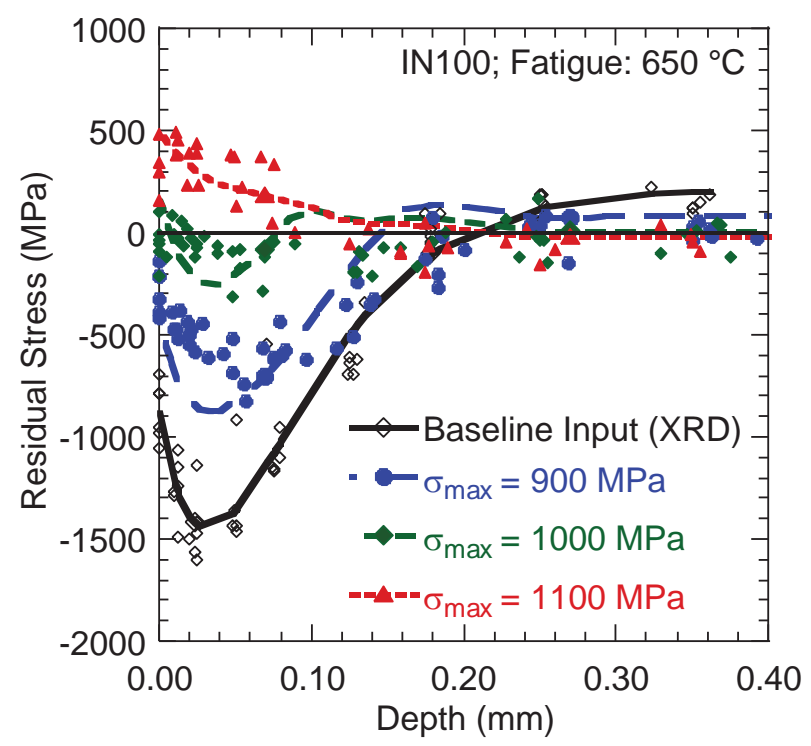

Figure 5. Experiment results (symbols) and model predictions (lines) for retained residual stress profiles in cylindrical dogbone specimens of shot peened IN100 at $650{ }^{\circ} \mathrm{C}$ after fatigue testing to different levels of maximum applied stress.

All fatigue specimens were cycled to failure prior to $\mathrm{x}$-ray diffraction measurement. Experimental results [19] show that under all of these loading conditions, relaxation of surface residual stresses occurs on the first cycle, with little or no additional relaxation with additional cycling. After failure, the specimen fracture surface was removed and the remaining gage section of the sample was used for residual stress depth measurements. All x-ray diffraction measurements were completed approximately 3-4 $\mathrm{mm}$ away from the end of the fracture surface to avoid influence from the free surface. The residual stress profiles in Figure 5 were measured in the direction of the applied maximum stresses of 900, 1000, and $1100 \mathrm{MPa}$. At each stress level, four to six individual specimens were measured and all the individual data points are displayed in this figure. The scatter in residual stress measurements after loading appears to be similar to the as-peened condition indicating that most of the scatter is associated with the peening process or residual stress measurement. The maximum applied stress of $900 \mathrm{MPa}$ retains a compressive surface residual stress while the $1000 \mathrm{MPa}$ is near zero and the $1100 \mathrm{MPa}$ has produced tensile residual stress on the 
surface and compression in the core. The cause for the tensile stress at the surface for the higher applied stresses was the large applied plastic strain over the entire cross-section of the sample. Finite element simulations reveal that yielding occurs first in the interior of the sample where the total tensile stresses are higher because of the superposition of the applied tensile stress and the compensatory tensile residual stress. In addition, the yield strength in the core is lower than that of the surface since it was not plastically deformed by the surface treatment process.

The finite element predictions of residual stress profiles for these three stress levels are shown as the different dotted lines shown in Figure 5. The residual stress profile is assumed to be equibiaxial and is only a function of depth into the surface. The residual stress data were incorporated into the finite element model using available Abaqus [20] initialization subroutines for stress and plastic strain. An available elastic-plastic model with non-linear mixed isotropic-kinematic constitutive model was employed in the finite element solution for relaxation of residual stresses. The round dogbone geometry was modeled using an axisymmetric finite element model of the gage section. In addition, the predictions only modeled one cycle since previous experiments have shown that practically all of the relaxation occurs on the first cycle. This was anticipated since the tests were performed in stress control and at a positive stress ratio, so no additional plastic strain occurs after the first cycle. Overall, the predictions capture the same trends as the measured x-ray diffraction depth profile data. More specifically, the predicted profiles show similar stress magnitudes and shapes compared to the measurements. The prediction at a maximum stress of $900 \mathrm{MPa}$ does not show the same amount of relaxation as the data. This difference could be the result of only modeling one cycle, possible thermal relaxation over the course of the fatigue test, or variability in the residual stress shot peening profile from specimen to specimen. One important item to note is that all predictions use the same input residual stress profile in the analysis, which is the mean trend of several measurements. However, the individual specimens exhibit variability in their initial residual stress profile resulting in variability in the measured retained residual stress. Clearly, gross cross sectional yielding of the uniform gage section is easy to accomplish, but is unlikely to occur in actual components or structures in practice. However, large plastic strains localized at discontinuities such as holes, fillets, and radii are expected. The effects of these discontinuities are addressed next.

\section{$\underline{\text { Relaxation under Notched Gradient Stress Profile }}$}

To investigate retained residual stresses in shot peened specimens with notches a finite element model was developed of a cylindrical dogbone specimen with a circumferential notch similar to that shown in Figure 1. The actual notched specimen had a notch radius of $2.5 \mathrm{~mm}$ resulting in an elastic net-section stress concentration factor, $\mathrm{K}_{\mathrm{t}}$, of 1.7. The specimen was designed such that the net section area at the notch was the same as the area in the cylindrical dogbone specimen with uniform gage section shown in Figure 1. This allowed the two geometries to be compared since they have a similar residual stress profiles and more importantly, the same compensatory tensile residual stress. The baseline profile shown in Figure 6 is the resulting baseline residual stress profile after the finite element code performed an equilibrium solution step on the user supplied residual stress profile that was input into the model using available Abaqus [20] initialization subroutines.
Predictions for retained residual stress depth profiles for a single mechanical loading cycle in this notch geometry were performed at the same net section stress levels and temperature as the smooth dogbone, as shown in Figure 6. Although the applied net section stresses are above yield strength, the notch with the stress concentration factor also yields in tension. The result is that after unloading compressive surface residual stress remains at the notch.

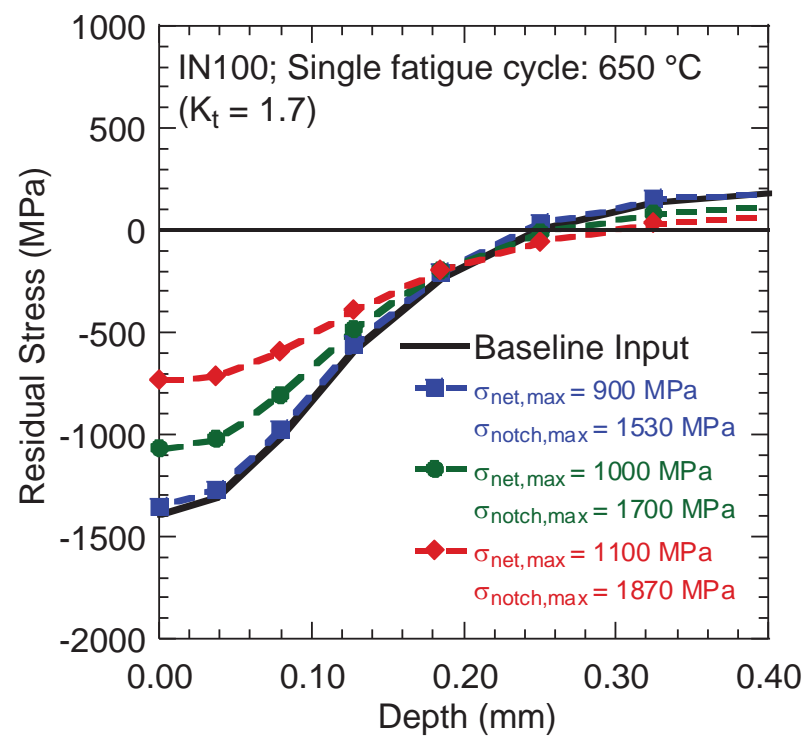

Figure 6. Model predictions for retained residual stress profiles in cylindrical notched geometry in shot peened IN100 at $650{ }^{\circ} \mathrm{C}$ after the application of different levels of maximum applied stress.

These predictions cannot be easily be verified with $\mathrm{x}$-ray diffraction measurements because of the small size of the notch. Typically, x-ray diffraction irradiated regions are usually no smaller than $1 \mathrm{~mm}$ in size. For this $2.5 \mathrm{~mm}$ radius notch, $\mathrm{x}$-ray measurements over a $1 \mathrm{~mm}$ irradiated region would average the stresses over a large stress gradient producing erroneous measured stress values. X-ray diffraction measurements on large notched specimens with a rectangular cross-section, reported by Buchanan and John [17], demonstrated that compressive residual stresses are retained at the notch after large plastic strains. For notched components or structures where gross cross section yielding is unlikely to occur and where stress concentration factors are usually present, compressive surface residual stresses are likely to remain after thermomechanical loading.

\section{$\underline{\text { Relaxation under Bending Gradient Stress Profile }}$}

To summarize current relaxation results so far, it was shown that the uniform cross-section geometry subject to large plastic strains resulted in reversal of the shot peened stress profile with tensile stresses on the surface after unloading. In contrast, the notched geometry, with an applied stress gradient across the net section and the maximum stress at the notch root, resulted in retained compressive stresses at the notch surface after unloading. In both of these two prior cases, an applied tensile stress was superimposed with the shot peened residual stress profile. To investigate applied stress gradients with compressive stress values superimposed with compressive shot peened stresses as shown in Figure 1 requires a flat specimen geometry and a four-point 
bending loading fixture, as shown in Figure 7 . The four-point fixture produces a linear stress gradient through the thickness superimposed with the residual stress profile as shown in Figure 8.

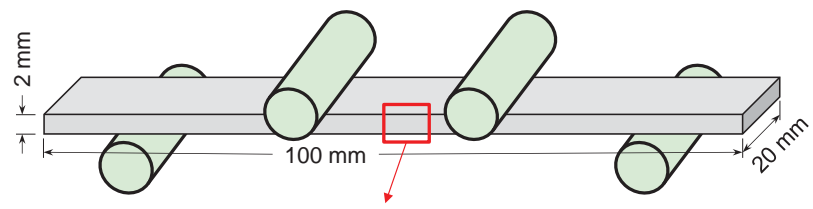

Figure 7. Schematic representation of four-point bend loading fixture with specimen geometry and rollers.

Furthermore, the stress profile is constant along the long axis of the sample between the upper rollers. This large surface area is ideal for experimental measurement of strain and residual stress. This configuration allows simultaneous superposition of applied compressive stress with compressive residual stress on the top surface and applied tensile stress with compressive residual stress on the bottom surface as shown in Figure 8. The applied stress at the center of the sample is zero. This is in contrast to the axially loaded uniform and notched samples discussed previously.

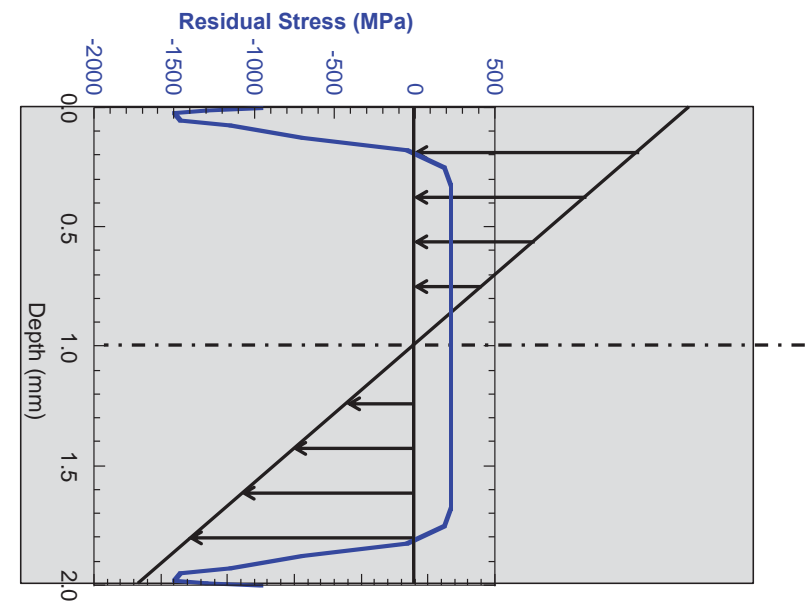

Figure 8. Schematic representation of four-point bend loading fixture with specimen geometry and rollers.

Figure 9 shows from top to bottom views of the top, side, and bottom surfaces of the bend specimen. The side view in the middle shows the roller position in the four-point bend fixture and the deformed specimen shape during loading and after permanent deformation. The top and bottom views show placement of strain gages used to measure strain on the top and bottom surfaces during deformation and residual stress measurement locations after completion of the test. As mentioned earlier, the four-point bend fixture produces uniform stress along the long axis of the specimen, which provides sufficient surface area for strain gages and residual stress measurement locations. Furthermore, the distance between the top rollers was set to $40 \mathrm{~mm}$ to provide sufficient distance between the rollers and the measurement region. In addition, the stress profile is also constant along the width direction (short axis) of the sample. This enabled the strain gage and residual stress measurement locations to be staggered along the width direction and be subjected to the same applied and residual stresses.
The complete load-unload computed bending stress versus measured strain deformation response of the four-point bend samples for three maximum applied stresses of interest in IN100 at room temperature are shown in Figure 10. All three specimens were tested in the shot peened condition and upon unloading, resulted in permanent deformation as shown in Figure 9.
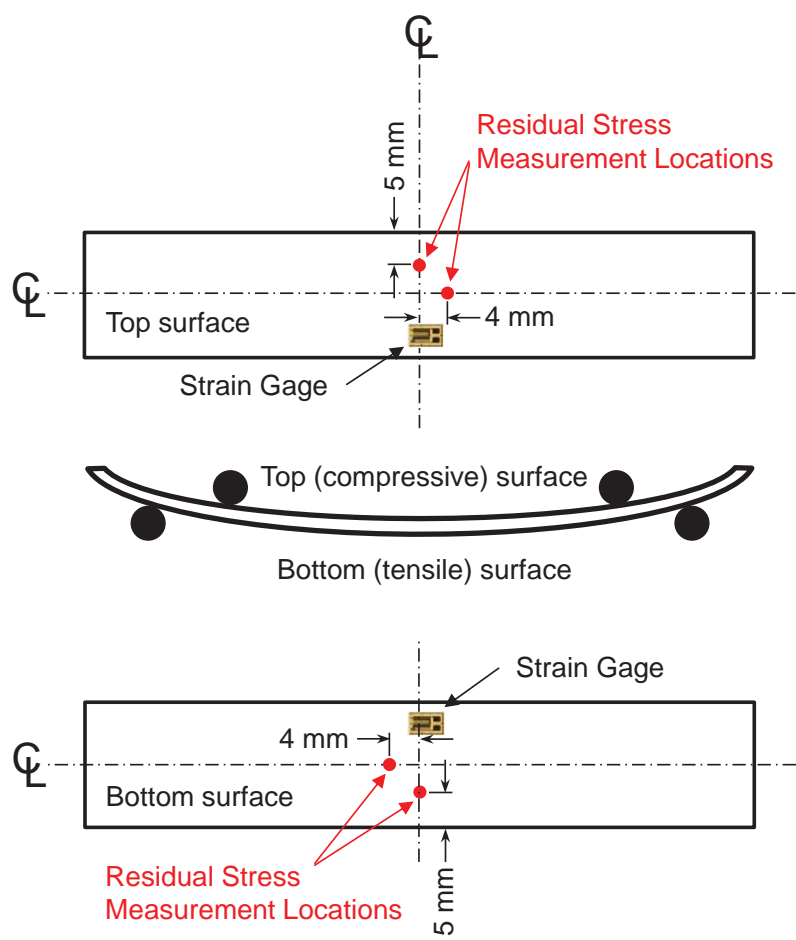

Figure 9. Bend specimen schematic showing locations of strain gages and residual stress measurement locations on both the top (compressive) and bottom (tensile) surfaces.

The elastic modulus, measured in the elastic region of the curve was determined to be $207 \mathrm{GPa}$. This was within $1.5 \%$ of the measured value from the uniaxial value reported in Figure 2, which indicates that the computed measured stresses and strains are accurate. The plastic strain levels for maximum applied surface stresses of 1268,1364 , and $1512 \mathrm{MPa}$ were approximately $0.0022,0.0035$, and 0.006 , respectively. All the compressive strains shown in Figure 10 were measured on the top surface of the specimens with the sign changed to plot as positive values. Interestingly, strain measurements recorded simultaneously on the bottom surface were practically identical in magnitude to the top surface showing no difference in yield behavior under tension and compression.

Measurements of retained residual stress depth profiles on the tensile and compressive surfaces of shot peened IN100 four-point bend samples tested at $23{ }^{\circ} \mathrm{C}$ are shown in Figures 11 and 12. The residual stress measurements were completed by American Stress Technologies, of Pittsburgh, PA using their Prism ${ }^{\circledR}$ technique [21], which is an electronic speckle pattern interferometry hole drilling technique. However, the baseline profile is the as-peened residual stress profile measured using x-ray diffraction averaged from multiple samples and the solid line is a trend line fit to the data. 


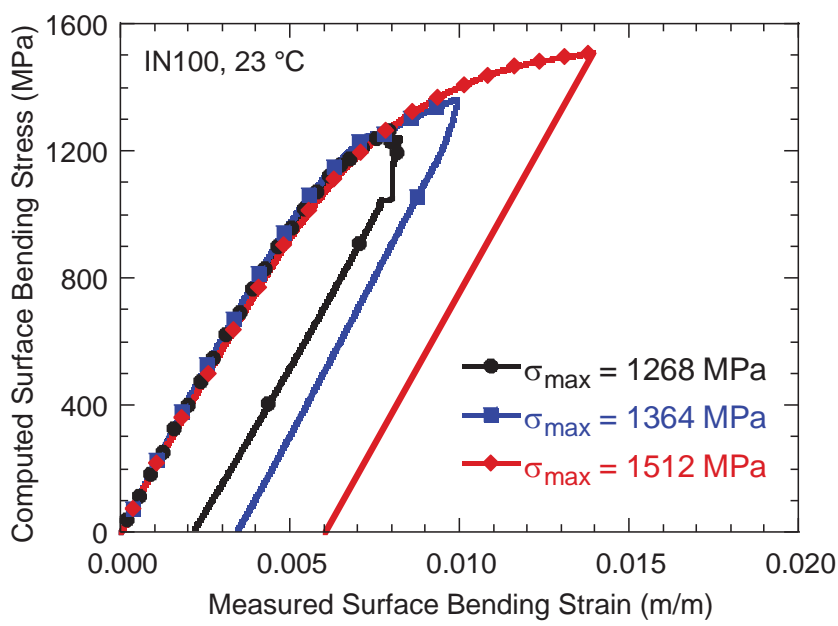

Figure 10. Stress-strain response and resulting plastic deformation for shot peened IN100 at $23{ }^{\circ} \mathrm{C}$ for different levels of maximum bending stress.

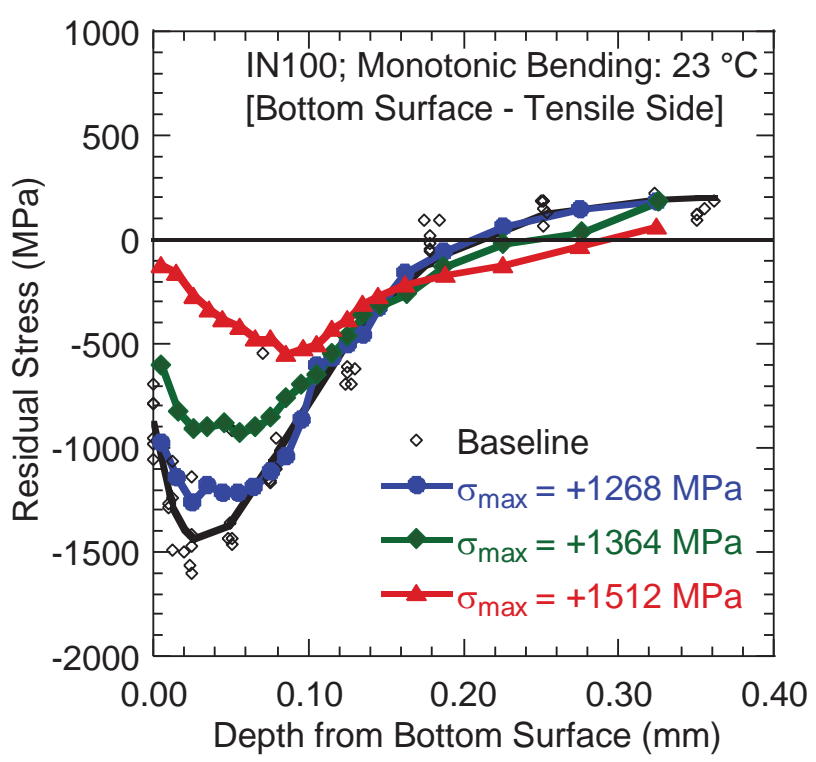

Figure 11. Effect of applied stress gradient on retained residual stress on the bottom surface of the bend specimen for different levels of applied tensile stress.

All residual stress measurements were completed in an approximately $10 \mathrm{~mm}$ region in the middle of the sample away from the rollers to avoid influence from the applied load as shown in Figure 9. The residual stress profiles in Figure 11 were measured on the bottom surface in the long-axis orientation, which is the applied loading direction for applied maximum tensile stresses of $+1268,+1364$, and $+1512 \mathrm{MPa}$ based on elastic beam theory. On the bottom surface the applied tensile stress from bending is superimposed with the compressive residual stress from shot peening, which after unloading results in some level of relaxation. The maximum applied stress of $+1268 \mathrm{MPa}$ appears to exhibit little or no relaxation in residual stress whereas the other two profiles exhibit increased relaxation with increased applied tensile stress. These relaxation trends with increasing applied stresses are similar to those observed in Figure 5 and Figure 6 for uniform and notched geometries, respectively. In contrast, residual stress profiles shown in Figure 12 were measured on the top surface in the long-axis orientation, which is the applied loading direction for applied minimum compressive stresses of $-1268,-1364$, and $-1512 \mathrm{MPa}$.

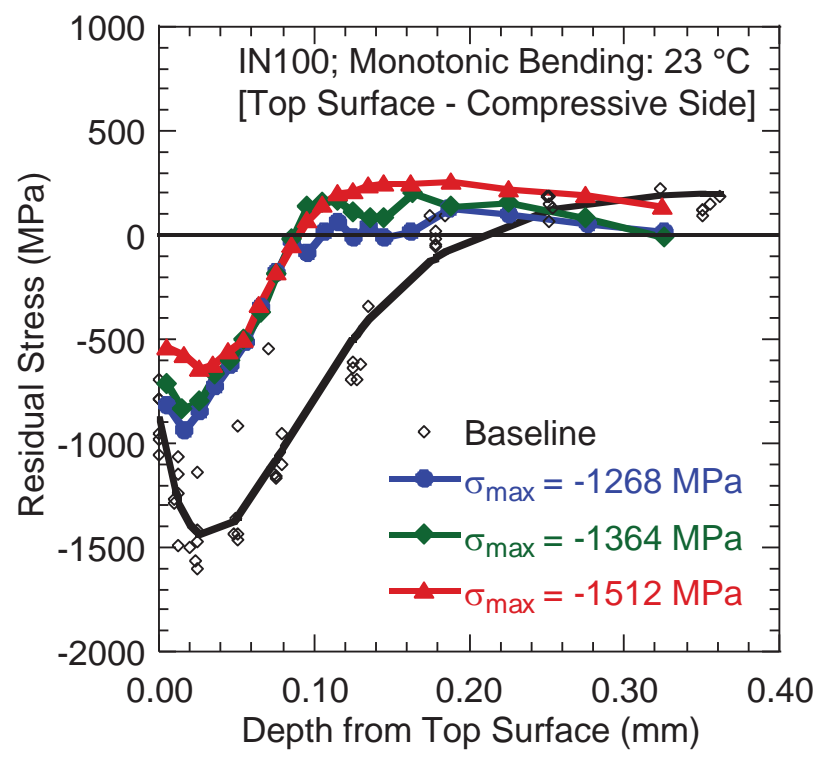

Figure 12. Effect of applied stress gradient on retained residual stress on the top surface of the bend specimen for different levels of applied compressive stress.

On the top surface the applied compressive stress from bending is superimposed with the compressive residual stress from shot peening, which after unloading results in some measure of relaxation. However, on the top surface of the specimen, the final residual stress profiles are similar with only a limited difference in relaxation with increased applied compressive stress. The residual stress relaxation behavior on the two surfaces of the bend geometry are clearly different from each other. This difference in relaxation behavior between the two surfaces is intuitive, given the interaction of an asymmetric applied stress gradient with a symmetric residual stress profile.

Even though the observation that all three geometries exhibited some level of residual stress relaxation, the cause for relaxation is different for the different geometries. In the uniform loading geometry, large applied tensile stresses (900-1100 MPa) were superimposed with compensatory tensile residual stresses are about $200 \mathrm{MPa}$ in the core of the sample. The core is where yielding initiated, causing stress relaxation in the sample after unloading. In the notched geometry the same net section stresses were applied producing much larger stresses at the notch with lower than nominal stresses in the core. The tensile core was again responsible for relaxation of residual stresses, but since the applied stresses in the core were smaller compared to the uniform geometry, much of the compressive surface residual stress remained at the notch after unloading. Furthermore, tensile yielding at the notch during loading contributed to the compressive stress at the notch after unloading. Finally, in the bending geometry much larger applied stresses (1268 $1512 \mathrm{MPa}$ ) were required to produce yielding, which was the result of superposition of the tensile core with the applied tensile stress on the bottom surface. In addition, there was compressive yielding on the top surface from the superposition of the shot 
peened compressive surface with the applied compressive stress. These resulted in different residual stress profiles on opposite surfaces because of the asymmetric applied bending stress profile.

\section{Conclusions}

Tensile, fatigue, and bend tests on shot peened IN100 were completed at room and elevated temperature. X-ray diffraction and Prism ${ }^{\circledR}$ hole drilling were used to measure the residual stress depth profiles after mechanical loading. Residual stress relaxation behavior subject to large plastic strains was investigated under a uniform loading, a stress gradient at notch, and a stress gradient from bending. The experimental results and predictions reveal that for uniform gage sections with large applied stresses, or plastic strains, the residual stress profile can be redistributed leaving tensile stress on the surface after unloading. However, in the case of a notched geometry with similar applied stresses, compressive surface residual stresses remain at the notch after unloading. The bend geometry also retained compressive residual stress profiles, but the two surfaces exhibited different levels of relaxation.

\section{Acknowledgements}

This work was performed at the Air Force Research Laboratory, Materials and Manufacturing Directorate (AFRL/RXCM), Wright-Patterson Air Force Base, $\mathrm{OH}$ 45433-7817 under on-site contract number FA8650-14-D-5205. The authors gratefully acknowledge experiment support from Messrs. Mark Ruddell and Philip Blosser in conducting the mechanical tests.

\section{References}

1. P. Prevéy, D. Hornbach, and P. Mason, "Thermal Residual Stress Relaxation and Distortion in Surface Enhanced Gas Turbine Engine Components," Proceedings of the 17th Heat Treating Society Conference and Exposition and the 1st International Induction Heat Treating Symposium ed. D.L. Milam et al., (Materials Park, OH: ASM, 1998), 3-12.

2. T.P. Gabb et al., "Stress Relaxation in Powder Metallurgy Superalloy Disks," TMS Letters, 1 (2004), 115-116.

3. J. Ahmad et al., "An Assessment of Residual Stresses Induced by Surface Treatments," Proceedings of the 6th National Turbine Engine High Cycle Fatigue Conference (Jacksonville, FL: Universal Technology Corporation, 2001).

4. W. Cao et al., "Thermomechanical Relaxation of Residual Stress in Shot Peened Nickel Base Superalloy," Material Science and Technology, 10 (1994), 947-954.

5. H. Holzapfel et al., "Residual Stress Relaxation in an AISI 4140 Steel due to Quasistatic and Cyclic Loading at Higher Temperatures," Material Science and Engineering: A, 248 (1998), 9-18.

6. P. Prevéy, "The Effect of Cold Work on the Thermal Stability of Residual Compression in Surface Enhanced 718," Proceedings of the 20th ASM Materials Solution Conference \& Exposition (St. Louis, MO: ASM International, 2000).
7. D.J. Buchanan, R. John, and N.E. Ashbaugh, "Thermal Residual Stress Relaxation in Powder Metal IN100 Superalloy," Journal of ASTM International, 3 (2006).

8. J. Lu, J.F. Flavenot, and A. Turbat, "Prediction of Residual Stress Relaxation During Fatigue," Mechanical Relaxation of Residual Stresses: ASTM STP 993, ed. L. Mordfin (Philadelphia, PA: American Society for Testing and Materials, 1988), 75-90.

9. J.L. Chaboche, and O. Jung, "Application of a Kinematic Hardening Viscoplasticity Model with Thresholds to the Residual Stress Relaxation," International Journal of Plasticity, 13 (1998), 785-807.

10. W.Z. Zhuang, and G.R. Halford, "Investigation of Residual Stress Relaxation Under Cyclic Load," International Journal of Fatigue, 23 (2001), 31-37.

11. L. Liu, and H. Yuan, "Prediction of Residual Stress Relaxation in Shot-Peened Specimens and its Application for the Rotor Disc Assessment," Material Science and Engineering A, 527 (2010), 6690-6698.

12. R.C. McClung, "A Literature Survey on the Stability and Significance of Residual Stresses During Fatigue," Fatigue Fract Engng Mater Struct, 30 (2007), 173-205.

13. D.J. Buchanan, M.J. Shepard, and R. John, "Retained Residual Stress Profiles in a Laser Shock-Peened and ShotPeened Nickel Base Superalloy Subject to Thermal Exposure," International J. of Structural Integrity, 2 (2011), $34-41$.

14. O. Vöhringer, "Relaxation of Residual Stresses," Proceedings of the European Conference on Residual Stresses, ed. E. Macherauch and V. Hauk, (Karlsruhe, Germany: Ir Pubns Ltd, 1983), 47-80.

15. D. Kirk, "Effects of Plastic Straining on Residual Stresses Induced by Shot-Peening," Proceedings of the Third International Conference on Shot Peening, ed. H. Wohlfahrt, R. Kopp and O. Vöhringer, (Garmisch-Partenkirchen, Germany: 1987), 213-220.

16. P. Prevéy, M.J. Shepard, and P.R. Smith, "The Effect of Low Plasticity Burnishing (LPB) on the HCF Performance of FOD Resistance of Ti-6Al-4V," Proceedings of the 6th National Turbine Engine High Cycle Fatigue Conference (Jacksonville, FL: Universal Technology Corporation, 2001).

17. D.J. Buchanan, and R. John, "Residual Stress Redistribution in Shot Peened Samples Subject to Mechanical Loading," Materials Science \& Engineering A, 615 (2014), 70-78.

18. K. Li, N.E. Ashbaugh, and A.H. Rosenberger, "Crystallographic Initiation of Nickel-Base Superalloy IN100 at RT and $538^{\circ} \mathrm{C}$ Under Low Cycle Fatigue Conditions," Superalloys 2004, ed. K.A. Green et al. (Warrendale, PA: The Minerals, Metals \& Materials Society, 2004), 251-258. 
19. R. John et al., "Stability of Shot Peen Residual Stresses in IN100 Subjected to Creep and Fatigue Loading," Procedia Engineering, 2 (2010), 1887-1893.

20. Abaqus v6.12, "User Subroutine Reference Manual”, (Providence RI: Abaqus, Inc., 2014).

21. G.S. Schajer and M. Steinzig, "Full-field Calculation of Hole Drilling Residual Stress from Electronic Speckle Pattern Interferometry Data," Experimental Mechanics, 45 (6) (2005), 526-532. 